\title{
Relación médico-paciente y mercado de la salud en Colombia
}

Jorge Márquez $\mathrm{V}^{(\mathrm{a})}$

\section{Medicina occidental, medicalización y biopolítica}

Con ayuda de la narrativa histórica, hay que delimitar primero varios conceptos y campos. Ante todo el campo de conocimiento llamado "medicina occidental", no comprendido desde sus orígenes en el mundo griego, sino solamente desde su expresión universitaria en la modernidad. La medicina certificada por cursos, exámenes y diplomas, basada en una gestión regulada e institucional de la enseñanza médica y de la validación de títulos. La misma que se convirtió en Occidente en monopolio de instituciones refrendadas por los Estados y legitimadas internacionalmente a través de la producción colectiva y de la sanción social de conocimientos científicos y técnicos y sus aplicaciones. La misma que ha llegado a ser, políticamente, una herramienta hegemónica y que, al menos desde el siglo xVIII, ha ampliado su poder hacia ámbitos externos, diferentes del cuerpo y la enfermedad, como la muerte, el nacimiento, la vejez, la infancia, la ciudad, la población. Esta extensión de dominios es lo que el historiador Michel Foucault llamó el "proceso de medicalización indefinida"1. Indefinida, por la forma en que se convierte en herramienta de una nueva tecnología de poder, sin prever de antemano sus límites ni a qué dominios de la sociedad y de la vida se podría extender. Lo que sí sabemos es que hemos llegado a un punto de una especie de "naturalización", es decir, cada vez nos queda más difícil concebir la sociedad sin medicalización y sin gobierno biopolítico.

\section{Mercado terapéutico y mercado global de la salud}

Otra manifestación de la modernidad es el fortalecimiento y la extensión del "mercado terapéutico" ("medical marketplace"). Este concepto, ampliamente utilizado y criticado por los historiadores, propuesto en 1986 por Harold Cook², permite definir los diferentes oferentes de cuidados y sus consumidores, en un momento de la modernidad en que las instituciones oficiales controlaban muy poco el ejercicio de la medicina, de ahí que los investigadores lo hayan utilizado sobre todo para el estudio de momentos en que el mercantilismo, aunado a la incapacidad de las instituciones para controlar los diversos oficios médicos, deja ver más un mercado de cuidados abierto hacia los posibles compradores que

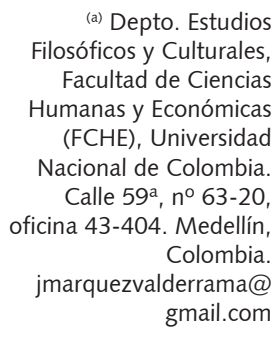

(a) Depto. Estudios Filosóficos y Culturales, Facultad de Ciencias Humanas y Económicas (FCHE), Universidad Nacional de Colombia. Calle 59a ${ }^{\circ} n^{\circ}$ 63-20, oficina 43-404. Medellín, Colombia. jmarquezvalderrama@ gmail.com 
una economía de la salud. En ese contexto, los médicos constituyen uno de los sectores económicos insertos en un mercado que se puede comprender como el conjunto de prestaciones de cuidados disponibles en un espacio determinado. Este concepto también ha sido determinante en la distinción de Brockliss y Jones ${ }^{3}$ entre "medical community", para referirse a la medicina oficial, y "medical penumbra", en la cual agrupan las artes de curar poco o nada reconocidas. Lo que se ha querido mostrar con los usos de este concepto, es la gran oferta de cuidados terapéuticos en el momento anterior a la formación de un monopolio de cuidados dominado por la medicina universitaria de pretensión científica.

Según el historiador William Bynum ${ }^{4}$, en la transición del siglo XVIII al siglo xIx, en Norteamérica y en Europa (excepto Francia), se planteó la pregunta sobre si el diploma de médico era o no necesario para ejercer la medicina. La respuesta casi siempre fue negativa, pues el liberalismo triunfó en casi todas partes. Si hubo algunas formas de regulación del ejercicio de la medicina fue por iniciativas de autoridades locales que se limitaban a ciertas jurisdicciones, y no propiamente por leyes nacionales. Además, las pocas reglamentaciones fueron puestas en práctica solamente en las ciudades, y perdieron toda vigencia por fuera del recinto urbano. La organización gremial y la fundación de universidades no hicieron desaparecer ese liberalismo de las prácticas médicas. Incluso si los médicos universitarios del siglo xIX conquistaron responsabilidades destacadas en situaciones sanitarias de peligro y en la organización de la salud pública, no contaban con los instrumentos ni con el apoyo políticos para lograr un monopolio de la oferta terapéutica ${ }^{4}$.

Ese monopolio llegó de manera desigual a muchos países, pero se volvió internacional con las convenciones sanitarias internacionales de la segunda mitad del siglo xIX y otros acuerdos de comienzos del siglo xx. Más tarde, en plena Segunda Guerra mundial, llegó a ser global, apoyado en los triunfos de la medicina científica. Difícil enumerarlos todos rápidamente: progresos en cirugía y en la lucha contra el dolor, mejoramiento de los medios diagnósticos (imagenología médica), inmunología y vacunas, terapéutica antibiótica, farmacología psiquiátrica, avances en genética, ensayos clínicos e industria farmacéutica, generalización y estandarización de las terapéuticas en la población mundial. Pero, sobre todo, quizás el logro más importante fue la consolidación de la prevención, basada en un conocimiento cada vez más exacto de las interacciones entre enfermedades evitables y medios de vida, en la observación cuantitativa de los fenómenos vitales y en la epidemiología. Todo esto ha hecho que la medicina occidental gane en confianza pública y en poder, y ha promovido un movimiento sanitarista desde el cual médicos y pacientes han luchado porque el estamento político reconozca la salud como un derecho fundamental.

Por otra parte, desde el periodo de posguerra, la extensión de los sistemas de seguridad social a muchos países nos situó en otro punto. Hoy habría que referirse, no al "mercado terapéutico", sino más bien al mercado global de la salud. Debemos reconocer esta actual doble cara del acceso a la salud: contractual-rentable y contractual-ciudadana. Ello es visible en varios aspectos: 1 La garantía de la salud depende de actores sociales privados y estatales. 2 En el mundo globalizado, la salud se concibe a la vez como una mercancía, un servicio y un derecho. 3 La salud sigue siendo un concepto individual ${ }^{5}$, pero solo puede ser garantizada a cada sujeto por vías institucionales, es decir, colectivas.

\section{Médico general y profesión médica}

Volviendo a la narrativa histórica, mientras la medicina ganaba poder y confianza, se fue afianzando la relación médico-paciente y con ella la profesión, mediante una institución que, quizás por íntima, se ha caracterizado por su bajo perfil público y su gran penetración social: la medicina general, que ha sido a la vez una práctica, una institución y un modo de acceso de la gente común a los avances de la ciencia y la técnica. En ciertos lugares, se trata de una institución en declive, o ya desaparecida, tanto que por todas partes se habla hoy de recuperarla. Los más inescrupulosos mercaderes de la salud, al menos en Colombia, nos quieren hacer creer que todavía existe, pero lo cierto es que, con la privatización del sistema de salud, las funciones del médico general y de la medicina familiar se han desvirtuado y muy pocas personas pueden gozar de un seguimiento personalizado. 


\section{La relación médico-paciente en las nuevas lógicas de mercado}

No voy a contar la historia que, en momentos diversos y por diferentes vías y modos, ha sucedido más o menos por todas partes: la del devenir hegemónico de la medina occidental, a la vez como oferta terapéutica, instrumento biopolítico y vía de distintas liberaciones y sujeciones del cuerpo.

Evoqué el momento de la modernidad, cuando la medicina occidental, además de profesión liberal, se convirtió en herramienta política y cuando emergió la salud pública, porque estamos viviendo hoy una nueva mutación importante de nuestra historia que involucra de lleno a la medicina. Además, porque quiero denunciar la distorsión de la relación médico-paciente mediante la exposición de algunos acontecimientos recientes del caso colombiano, pero que no son exclusivos de él.

Sin embargo, antes debo aclarar de qué manera comprendo la relación médico-paciente. Esta relación social y antropológica, llamada "coloquio singular" por algunos filósofos, tiene hoy gran vigencia, aunque la medicina basada en la evidencia pretenda que no trata con pacientes (realidades subjetivas), sino con fenómenos patológicos (realidades objetivas). El debate entre instrumentalismo y humanismo en medicina está vivo, y los médicos, los pacientes y todo el personal auxiliar de la medicina lo vive cotidianamente.

Nunca la medicina había sido tan poderosa, nunca había tenido tan finas herramientas para abordar nuestra realidad vital, nunca se había enfrentado tan bien armada a la enfermedad y a la muerte, y al mismo tiempo nunca había sido tan cuestionada, precisamente, en su poder y en los límites de ese poder. Nunca antes, como en nuestros días, se le había usurpado tanto su poder.

Para entender esta paradoja del poder médico del siglo xxı, hay que distinguir los poderes de la medicina y los que la rondan para apoderarse de ella. Ante todo, hay que distinguir el poder médico expresado en la medicalización creciente de la vida y el poder inherente a la relación médico-paciente. El filósofo François Dagognet ha descrito este último ${ }^{6}$. Argumenta que la relación terapéutica pierde sentido cuando el médico cede el poder inmanente de su oficio, cuando no puede decidir sobre la vida, la enfermedad y la salud, a partir de su función especial en la relación clínica. Y continúa Dagognet:

[...] hay que evitar, en toda circunstancia, que el médico y el paciente pierdan su campo de libre entendimiento, el que además garantiza la eficacia del tratamiento. Impidamos la confiscación de lo médico por un poder cuyo ejercicio debemos favorecer, pero cuyo dominio debemos reducir. No es que queramos, a cualquier precio, "una especie de extraterritorialidad" a favor de la terapéutica, lo que queremos es limitar la entrada de un tercero en el acto médico, un tercero que confiscaría para su propia ventaja ese momento o esa relación sin igual, fundada sobre la humanidad y el puro auxilio, fuera de todo imperativo económico o de seguridad ${ }^{6}$. (p. 256)

\section{La salud como derecho fundamental}

Hecha esta aclaración, debo anotar que en Colombia, como en otros países del mundo, en la década de 1940 se estableció el derecho a enfermarse por la vía de la medicina del trabajo (Ley 90 de 1946). Este acontecimiento se inscribe en el proceso de instauración del Estado keynesiano, que impulsó la creación de instituciones para la atención de los servicios sociales?.

Aunque no se trate todavía de una declaración constitucional del derecho a la salud, que solo llegará después de la Asamblea Nacional Constituyente y la nueva Constitución de 1991, y aunque haya funcionado de manera limitada, en la década de 1940 comenzó a operar un sistema de responsabilidad triple en el aseguramiento de la enfermedad y discapacidad de trabajadores y trabajadoras. Un tipo de seguro social en el cual el Estado, el empleador y el trabajador, cada uno en proporciones diferentes, financiaban con antelación la posible enfermedad o discapacidad del trabajador; es el comienzo del seguro social de enfermedad. Sin embargo, más que sus alcances, lo importante de este acontecimiento es haber generado el debate que dio nacimiento, en 1946, al Instituto Colombiano de los Seguros Sociales (ICSS) ${ }^{7}$.

El seguro de enfermedad permitió hacer respetar el derecho a enfermarse, es decir que los trabajadores cesantes por causa de enfermedad o discapacidad pudieran seguir recibiendo su salario 
o fueran recompensados en caso de enfermedad profesional o de accidente de trabajo. Este es el tránsito de un sistema asistencialista, en el cual los cuidados en salud son concebidos como una prebenda de los poderosos para con los débiles, hacia una política y una economía de la salud en cuyo marco comienza a debatirse la recuperación y la conservación de la salud como una reivindicación, primero, de los trabajadores y, más tarde, de la población en general. En la década de 1960 aparecerán la epidemiología social y la salud pública, desde las cuales se considerará la salud como un derecho de los ciudadanos en general.

Al comenzar la década de 1990, cuando el sistema de seguridad social colombiano llevaba cuatro décadas en funcionamiento, es decir, cuando apenas dos generaciones de colombianos habían disfrutado de él, se inició su desmonte gradual por parte de gobiernos que obedecían las políticas de privatización del Banco Mundial y los intereses de multinacionales y de empresas locales del mercado de los seguros. El propósito gubernamental al finalizar el siglo pasado era aumentar la cobertura en salud en el país y convertir la salud en un servicio financiado por los propios usuarios. Lo que lograron fue convertir rápidamente la salud en una mercancía, mediante la construcción paulatina de lo que hoy en Colombia se llama el "cartel de la salud"(b).

Con la Ley 100 de 1993, aprobada bajo el gobierno de César Gaviria Trujillo, presidente promotor de la apertura económica, el neoliberalismo y la privatización de las empresas estatales, se instauró el sistema de salud privatizada de gran cobertura, mediante la obligación para cada colombiano y colombiana de afiliarse a una aseguradora de salud o EPS (Entidad Promotora de Salud) y cotizar en ella mensualmente. Con este sistema, las contribuciones ciudadanas al sistema de salud, las llamadas "cotizaciones", pasaron a ser administradas por empresas privadas o EPS, las cuales debían reinvertir los millonarios recursos en el mejoramiento del sistema de atención. Sin embargo, las más poderosas, sin ningún escrúpulo, robaron millonarias sumas para invertirlas en la construcción de canchas de golf, hoteles, resorts, clubes y condominios de lujo y en cuentas secretas en paraísos fiscales del mundo. Esto es lo que se conoce como "el escándalo de la salud", de $2011^{8}$.

El proceso de privatización de la salud fue acelerado y fortalecido durante los dos gobiernos de Álvaro Uribe Vélez, entre 2002 y 2010. Como un ejemplo entre otros, en menos de 15 años, Carlos Palacino, presidente y uno de los principales dueños de una gran empresa, Saludcoop, creó un emporio de traficantes de la salud que llegó a mover 1.300.000 dólares al año, con 4 millones de usuarios cotizantes. A pesar de las denuncias del robo al Estado perpetrado por su compañía durante años, pero solamente denunciado penalmente en 2011 (denuncias confirmadas incluso por el actual presidente Juan Manuel Santos), hasta ahora la justicia no ha fallado en contra de los acusados, todos identificados ${ }^{(\mathrm{c})}$.

Este sistema de salud resultó ser muy rentable para empresarios privados (renta bruta de más 30 millones de dólares al año), pero totalmente contrario a la conservación de la salud y de la vida ${ }^{(\mathrm{d})}$, al fomento de la vida digna. Al limitar el acceso a la salud, el sistema de salud colombiano ha contribuido a agudizar la desigualdad social. Las cifras recientes son desoladoras: la concentración del ingreso en el país creció en un $8 \%$ en 2012, y continúa en el mismo nivel y en la misma tendencia hacia la desigualdad registrada en 2003 . Colombia es el segundo país más desigual de Latinoamérica, después de Haití10. (b) Comúnmente, en

nuestras sociedades, el funcionamiento asociativo en forma de cartel con fines de lucro es atribuido a organizaciones ilegales y mafiosas, pero cada vez más en las economías legales se utiliza este mecanismo por el cual se forman subrepticiamente monopolios para impedir la libre competencia en algún sector económico. Colombia es buen ejemplo de un país donde las aseguradoras y otras empresas del sector

financiero han encontrado en el mercado de la salud un terreno fértil para adoptar el mecanismo del cartel, que les permite aplastar a los pequeños competidores y multiplicar los beneficios.

(c) Aunque no ha habido proceso penal, solo investigación, ya hubo un fallo de responsabilidad fiscal de primera instancia emitido por la Contraloría General de la República, en el cual se condenó a Carlos Palacino, exdirector de la EPS SaludCoop, a pagar $\$ 1,4$ billones de pesos, y se sancionó a 15 funcionarios de la EPS y empresas afiliadas $^{9}$.

(d) Véase al respecto: Foro "Análisis y alternativas de la reforma de la salud", organizado por la Facultad de Medicina de la Universidad Nacional de Colombia el 21 de mayo de 2013. Los panelistas coincidieron en que la reforma a la salud es urgente y necesaria para el bienestar de los colombianos y para acabar con el negocio de las EPS ${ }^{11}$. 
(e) Algunos estudios recientes sobre este problema son los de Alzate et al. ${ }^{12}$ y Mario Hernández ${ }^{13}$.

(f) En Colombia la mayor parte de los medicamentos esenciales cuestan dos veces más que en Europa o en Estados Unidos $^{9}$

(g) Se han cerrado muchos hospitales; han desaparecido varios hospitales universitarios y hay 14 hospitales públicos de distinto nivel que tendrán que cerrar por falta de fondos.

\section{¿Cuáles son las razones del fracaso del sistema de salud colombiano? Un ejemplo: el "paseo de la muerte"}

La desigualdad aumenta la vulnerabilidad social, y el modelo neoliberal de administración empresarial de la salud, al menos en Colombia, fue un completo fracaso $^{(e)}$. Las razones de esto son múltiples, pero la principal ha sido la deficiente atención de los usuarios.

El ejemplo más patético lo constituye la atención de urgencia en Colombia que, en los últimos años, ha sido frecuentemente negada. Se considera atención de urgencia la necesaria para evitar el peligro de muerte del paciente. Muchos pacientes se ven obligados a recorrer diversos centros de urgencias y hospitales de una o de varias ciudades, antes de morir por falta de atención. A esta situación los periodistas la han llamado "el paseo de la muerte". Los centros hospitalarios que niegan la atención aducen razones como la falta de afiliación o la falta de identificación de los pacientes, quienes deben portar algún comprobante de afiliación u otras excusas semejantes, a pesar de que las leyes colombianas protegen la vida de las personas en peligro de muerte y prohíben la exigencia de requisitos en semejante situación ${ }^{14}$.

Cito el ejemplo del "paseo de la muerte" por ser extremo y patético, pero habría que sumarle las trabas innumerables para la negación de servicios pre-pagados, las inmensas filas para cualquier trámite, los precarios servicios de urgencias que parecen enfermerías de guerra, las dificultades para acceder a los medicamentos ${ }^{(f)}$, la disuasión a los médicos para que solo empleen 15 minutos con cada paciente y para que no prescriban ciertas pruebas diagnósticas y determinados tratamientos no incluidos en el Plan Obligatorio de Salud (POS). En fin, se trata de un sistema en el cual muchos pacientes mueren de enfermedades comunes y tratables, casos que, en su mayoría, no se reportan a los observatorios epidemiológicos, a causa del mismo déficit en la atención.

\section{La urgente reforma del sistema de salud colombiano}

\section{¿En qué consiste la coyuntura actual de urgente reforma del sistema de salud colombiano?}

Del millonario desfalco, revelado en 2011, se beneficiaron de manera fraudulenta los grandes operadores privados o EPS. Estos, a su vez, llevaron a la quiebra a muchos de los pequeños operadores privados y a una parte de los centros de atención de la red hospitalaria pública ${ }^{(\mathrm{g})}$. Hay que aclarar que los pequeños operadores privados (Instituciones Proveedoras de Servicios de Salud, IPS) y los hospitales públicos han trabajado de manera ardua durante años para las grandes EPS. Estas últimas, sea por la intervención estatal de que son objeto, sea porque se declaran ilíquidas o porque se niegan a hacerlo, no pagan sus enormes deudas a IPS y hospitales, y esa es la principal razón de que estos caigan en la bancarrota.

\section{Los jueces deciden en lugar de los médicos}

A partir del gran desfalco revelado en 2011 se habla en Colombia de la "crisis de la salud". Pero hacía tiempo que la salud colectiva ya estaba en crisis, pues, desde la adopción de la Ley 100 de 1993 la atención médica ya era muy precaria, debido a las intermediaciones burocráticas y a los múltiples obstáculos ya descritos arriba. Hace varios años que habíamos llegado a la situación en que estamos hoy, en la cual la justicia se convirtió en la vía más frecuente para garantizar la 
Por otra parte, o quizás como consecuencia lógica, los pacientes y los médicos han sido completamente ignorados por el Gobierno en el trámite de la actual reforma. Nadie del gobierno se pronuncia sobre la crisis de los hospitales públicos. Mientras tanto, poderosos intermediarios mantienen sus socios y lobistas como legisladores de la salud de los colombianos.

\section{A manera de cierre}

Las siguientes líneas sirven de cierre, porque por ahora no puede haber conclusión, dado que estamos en un momento agudo de la crisis del sistema de salud colombiano.

La situación del sistema de salud en Colombia se puede resumir así: mientras los hospitales se declaran en quiebra, los profesionales de la salud se empobrecen y su profesión es precarizada y los pacientes reciben atención deficiente, ciertos intermediarios de la salud y multinacionales financieras y farmacéuticas se enriquecen gracias a la privatización de hecho.

Los juristas toman diariamente decisiones que deberían ser de la competencia de la relación entre el médico y el paciente. Gran parte de las decisiones médicas son resultado de fallos en procesos jurídicos ("acciones de tutela"); los economistas y los auditores deciden el gasto en salud, como si el médico, que es quien conoce la historia del paciente y lo ve en persona durante el "coloquio singular", no supiera o no debiera estar capacitado por las facultades de medicina para tomar decisiones.

Las compañías farmacéuticas se entrometen en la relación médico/enfermo, y la corrompen con su clientelismo y su tráfico de favores. Aquí también le corresponde a la sabiduría del arte médico oponerse al ensañamiento terapéutico.

La relación médico-paciente debería respetarse en su ámbito propio de poder, es decir, no pervertirla con la intromisión de poderes ajenos a ella y a su objetivo. Esto vale también para el sistema de salud, en el cual los médicos deberían fortalecer su lucha actual por mantener su criterio profesional y humano en la defensa práctica del derecho a la salud y a la seguridad sanitaria. De la misma manera, en una escala mundial, le corresponde a la medicina evitar que los intereses comerciales se inmiscuyan en las decisiones sobre la seguridad sanitaria y sobre la salud de los pueblos. Es decir, evitar que la OMC piense por la OMS.

\section{Referencias}

1. Foucault M. Historia de la medicalización. Educ Med Salud. 1978; 12(1):3-22.

2. Cook HJ. The decline of the old medical regime in Stuart London. Ithaca: Cornell University Press; 1986.

3. Brockliss $\mathrm{L}$, Jones $\mathrm{C}$. The medical world of early modern France. Oxford: Clarendon Press; 1997.

4. Bynum WF. Médecine et société [XIXe siècle]. En: Grmek $M$, organizateur. Histoire de la pensée médicale en Occident: du romantisme à la science moderne. Paris: Seuil; 1999. v. 3, p. 295-317.

5. Canguilhem G. Écrits sur la médecine. Paris: Seuil; 1989.

6. Dagognet F. Savoir et pouvoir en médecine. Le Plessis Robinson (France): Synthélabo; 1998. 
7. Gómez J. La protección familiar en Colombia, 1946-1977 [tesis]. Bogotá: Facultad de Ciencias Humanas, Universidad Nacional de Colombia; 2011.

8. Guía básica para entender el escándalo en el sector de la salud. El Tiempo. 2011 Mayo 7; Sección Justicia [citado el 2013 Dic 7]. Disponible en: http://www.eltiempo.com/ justicia/ARTICULO-WEB-NEW_NOTA_INTERIOR-9304308.html

9. Colombia, un país enfermo por el alto costo de los medicamentos. El País. 2013 Jun 2; Sección Economía [citado el 2013 Dic 9]. Disponible en: http://www.elpais.com.co/elpais/ cali/noticias/colombia-pais-enfermo-por-alto-costo-medicamentos

10. Molina N. Colombia, segundo país con mayor desigualdad en Latinoamérica. En: Foro Pobreza en Colombia 2012; 2012; Colombia [citado el 2013 Nov 11]. Disponible en: http://www.colombialider.org/colombia-lider/colombia-segundo-pais-con-mayordesigualdad-en-latinoamerica

11. Universidad Nacional de Colombia, Facultad de Medicina, organizador. Foro Análisis y alternativas de la reforma de la salud; 2013; Colombia [citado el 2013 Dic 7]. Disponible en: http://www.agenciadenoticias.unal.edu.co/ndetalle/article/la-salud-ganancia-paralas-eps.html

12. Alzate D, Oviedo DG, Velosa L. Derecho lucro-destructivo: vivencias de la ideología posneoliberal en salud. En: Abadía C, Góngora A, Melo M, Platarrueda C, organizadores. Salud, normalización y capitalismo en Colombia. Universidad Nacional de Colombia, Universidad del Rosario: Ediciones desde abajo; 2013. p. 233-66.

13. Hernández M. Reforma a la salud: el proyecto del Gobierno legitima el negocio. Razón pública [Internet]. 2013 abril 1 [citado el 2013 Nov 11]. Disponible en: http://www. razonpublica.com/index.php/politica-y-gobierno-temas-27/3646-reforma-a-la-salud-elproyecto-del-gobierno-legitima-el-negocio.html

14. Colombia. Congreso de la República. Proyecto de ley 050 de 2012, por medio del cual se hace una adición al código penal, se crea el tipo penal de omisión u denegación de urgencias en salud. 2012 [citado el 2013 Nov 9]. Disponible en: http://www.senado.gov. $\mathrm{co} /$ sala-de-prensa/noticias/item/14655-un-alto-al-mal-Ilamado-paseo-de-la-muerte.

15. Lifstchitz E. ¿Qué son las enfermedades catastróficas? Observatorio de Salud. 2011. Ago.; 1(2): [4 p.] [citado el 2013 Nov 11]. Disponible en: http://www.consultordesalud. com.ar/admin/ediciones/pdfs/PDF_201188135248602.pdf

16. Vega $M$, Eslava J-C Arrubla D, Hernández $M$, organizadores. La reforma sanitaria en la Colombia de finales del siglo xx: aproximación histórica desde el análisis sociopolítico. Gerenc Polít Salud. 2012; 11(23):58-84.

17. Colombia. Congreso de la República. Texto conciliado al proyecto de ley estatutaria número 209 de 2013 Senado - 267 de 2013 Cámara, por medio de la cual se regula el Derecho Fundamental a la Salud y se dictan otras disposiciones. 2013 [citado el 2013 Nov 11]. Disponible en: http://www.consultorsalud.com/docs/Ley_Estatutaria_de_Salud_ junio2013.pdf 
Este artículo versa sobre el deterioro de la relación médico-paciente por el sistema de salud colombiano basado en principios neoliberales del mercado de la salud. Son tan numerosos los datos y las evidencias del deterioro de la atención en salud en Colombia durante las dos últimas décadas, que se hace innecesario emplear una metodología cuantitativa de administración de pruebas para denunciarlo. Aquí se muestra la precarización de la relación médico-paciente en Colombia, mediante testimonios de expertos y observación propia como usuario del sistema.

Palabras clave: Relaciones médico-paciente. Historia de la salud. Biopolítica. Reforma de la atención de salud. Salud Colectiva.

\section{The doctor-patient relationship and the healthcare market in Colombia}

This paper addresses the deterioration of the doctor-patient relationship within the Colombian healthcare system based on neoliberal principles of the healthcare market. The data on and evidence of the deterioration of healthcare services in Colombia over the past two decades are so numerous that it is unnecessary to use quantitative test management methodology to denounce this. Here, the way in which the doctor-patient relationship in Colombia has become precarious is shown through expert testimony and personal observation as a system user.

Keywords: Physician-patient relationship. Healthcare history. Biopolitics. Healthcare reform. Collective health.

\section{A relação médico-paciente e o mercado da saúde na Colômbia}

Este artigo trata da deterioração da relação médico-paciente pelo sistema de saúde colombiano, baseado nos princípios neoliberais do mercado da saúde. São tão numerosos os dados e as evidências da deterioração dos serviços de saúde na Colômbia durante as últimas duas décadas, que não é necessário utilizar uma metodologia quantitativa de gerenciamento de teste para denunciá-lo. Aqui se mostra a precarização da relação médico-paciente na Colômbia mediante testemunhas de especialistas e observações próprias como usuário do sistema.

Palavras-chave: Relação médico-paciente. História da saúde. Biopolítica. Reforma dos serviços de saúde. Saúde Coletiva. 
